\title{
Release of Volatile Compounds from Polymeric Microcapsules Mediated by Photocatalytic Nanoparticles
}

\author{
J. Marques, ${ }^{1}$ L. F. Oliveira, ${ }^{1}$ R. T. Pinto, ${ }^{1}$ P. J. G. Coutinho, ${ }^{1}$ P. Parpot, ${ }^{2}$ J. R. Góis, ${ }^{3}$ \\ J. F. J. Coelho, ${ }^{3}$ F. D. Magalhães, ${ }^{4}$ and C. J. Tavares ${ }^{1}$ \\ ${ }^{1}$ Centre of Physics, University of Minho, 4800-058 Guimarães, Portugal \\ ${ }^{2}$ Centre of Chemistry, University of Minho, 4710-057 Braga, Portugal \\ ${ }^{3}$ Chemical Engineering Department, Polo II, University of Coimbra, 3030-790 Coimbra, Portugal \\ ${ }^{4}$ LEPAE, Chemical Engineering Department, Faculty of Engineering, University of Porto, Rua Dr. Roberto Frias $s / n$, \\ 4200-465 Porto, Portugal
}

Correspondence should be addressed to C. J. Tavares; ctavares@fisica.uminho.pt

Received 14 January 2013; Accepted 24 January 2013

Academic Editor: Jiaguo Yu

Copyright (C) 2013 J. Marques et al. This is an open access article distributed under the Creative Commons Attribution License, which permits unrestricted use, distribution, and reproduction in any medium, provided the original work is properly cited.

In this study we propose a suitable method for the solar-activated controlled release of volatile compounds from polymeric microcapsules bonded with photocatalytic nanoparticles. These reservoirs can find applications, for example, in the controlled release of insecticides, repellents, or fragrances, amongst other substances. The surfaces of the microcapsules have been functionalized with $\mathrm{TiO}_{2}$ nanoparticles. Upon ultraviolet irradiation, redox mechanisms are initiated on the semiconductor surface resulting in the dissociation of the polymer chains of the capsule wall and, finally, volatilization of the encapsulated compounds. The quantification of the output release has been performed by gas chromatography analysis coupled with mass spectroscopy.

\section{Introduction}

Microencapsulation and release has been an area of growing interest in the last years due to the many application perspectives, like in pharmaceutical products for drug controlled release, such as of insulin and other proteins, or cosmetics [1-3]. Different approaches of microencapsulation have been reported in the last decade. The complex coacervation method is a technique that has been used to produce polymeric microcapsules $[4,5]$. This process uses the interaction of different polymers with opposite charges to form insoluble complexes and originate a phase separation. The encapsulation is achieved by the deposition of such complexes around a hydrophobic core. Despite the simple fabrication and ease of use in time-release and thermal-release applications, this method presents a significant number of disadvantages like wide-size distributions, weak shell wall, and low kinetics of shell wall formation $[6,7]$. Solvent evaporation is one of the most popular processes to achieve encapsulation. A core material, solid or liquid, and capsule wall material are mixed in a water-immiscible solvent and the resulting solution is emulsified in an aqueous solution $[8,9]$. After solvent evaporation, the solid microcapsules are produced. However this method requires quite complex processes and is expensive. Hence, interfacial polymerization emerged as an easy method to prepare microcapsules. It allows a high degree of control over the physical/chemical properties using mild reaction conditions [10]. This method involves the condensation reaction between two monomers dissolved in immiscible solvents at the interface, creating a thin polymer film. Due to its intrinsic advantages, this method was used in this work and the relationship between the properties of the water/oil phase and the polymeric capsule wall was carefully studied. It is well known that the experimental conditions are an important factor for controlling shape, permeability, and physical properties of the microcapsule $[11,12]$. Dodecane was used as oil phase and also as model organic volatile compound in which acyl chloride monomer was dissolved. An amine was dissolved in the water phase, resulting in the 
formation of polyamide film at the interface; as exemplified in Figure 1 [13].

The immobilization of titanium dioxide nanoparticles in microcapsules can offer a wide range of practical applications and combines the main advantages of photocatalytic reactions with the possibility of controlled release by solar activation. These photoactive nanomaterials can be deposited onto several types of surfaces, including tents, curtains, and windows, amongst other surfaces [14]. Semiconductor photocatalysts have attracted a great deal of attention because of their potential applications for removing toxic organic and inorganic pollutants $[15,16]$.

The main objective of this work was to produce polymeric microreservoir systems for the controlled release of volatile compounds (e.g., insecticides, deodorants, fragrances, etc.) upon solar activation. The $\mathrm{TiO}_{2}$ nanoparticles were synthesized by a modified sol-gel method and its microstructure was characterized by X-ray diffraction for different calcination temperatures. The controlled release of the encapsulated dodecane was studied in the presence of $\mathrm{TiO}_{2}$ catalysts with and without ultraviolet (UV) irradiation. In order to extend the semiconductor absorbance into the visible light region, aiming to reduce the semiconductor band gap, the $\mathrm{TiO}_{2}$ nanoparticles were doped with nitrogen anions [17].

\section{Experimental}

2.1. Materials. Titanium (IV) isopropoxide ( $>99 \%$, SigmaAldrich), propyl alcohol (>98\%, Sigma-Aldrich), triethylamine ( $>99 \%$, Sigma-Aldrich), hydrochloric acid (37\%, Sigma), poly(vinyl alcohol) (>98\%, Sigma-Aldrich), ethylenediamine ( $>99.5 \%$, Sigma-Aldrich), dodecane $(>99 \%$, Sigma-Aldrich), and sebacoyl chloride ( $>95 \%$, Sigma-Aldrich) were used as received. Commercial $\mathrm{TiO}_{2} \mathrm{P} 25$ powder was purchased from Degussa and used as reference photocatalytic material.

2.2. Synthesis of the N-Doped $\mathrm{TiO}_{2}$ Powders. The N-doped $\mathrm{TiO}_{2}$ nanoparticles were synthesized by a modified sol-gel method [18]. Triethylamine was used as nitrogen source for the attempted anionic doping of the $\mathrm{TiO}_{2}$ lattice. In a typical procedure, a solution was prepared with water and propyl alcohol (1:10) at $\mathrm{pH} 2.4$ (adjusted by addition of $\mathrm{HCl}$ ). $\mathrm{N}$-doped $\mathrm{TiO}_{2}$ nanoparticles were prepared by dissolving $1 \mathrm{~mL}$ of titanium isopropoxide in $1.25 \mathrm{~mL}$ of solution under vigorous stirring followed by a dropwise addition of $3 \mathrm{~mL}$ of nitrogen precursor. The reaction was carried out under gentle stirring for two days to attain the particle doped with nitrogen.

After the sol-gel synthesis, the $\mathrm{N}$-doped $\mathrm{TiO}_{2}$ nanoparticles were collected by repeated centrifugation and washed with propyl alcohol. Amorphous powders were first annealed at $80^{\circ} \mathrm{C}$ in a conventional electric oven for $8 \mathrm{~h}$ and later calcined at $300^{\circ} \mathrm{C}, 500^{\circ} \mathrm{C}, 700^{\circ} \mathrm{C}$, and $800^{\circ} \mathrm{C}$ during $2 \mathrm{~h}$ to produce nanometric powders. The resulting samples were named considering the calcination temperature as NP300,
NP500, NP700, and NP800, respectively. The sample without any thermal treatment was identified as NPRT.

2.3. Photocatalytic Activity. The photocatalytic oxidation of methylene blue (MB) in the presence of the $\mathrm{N}$-doped $\mathrm{TiO}_{2}$ nanoparticles under UV irradiation was investigated in order to evaluate the photocatalytic activity at different calcination temperatures [19-22]. The same procedure was performed for the reference $\mathrm{TiO}_{2} \mathrm{P} 25$ powder.

In a typical experiment, $2 \mathrm{mg}$ of photocatalyst was suspended in aqueous methylene blue solution $\left(10^{-5} \mathrm{M}\right)$ in a quartz cell $(40 \mathrm{~mm} \times 40 \mathrm{~mm} \times 10 \mathrm{~mm})$ at $\mathrm{pH} 7.2[23,24]$. The suspension was irradiated with a high power LED source (Thorlabs, $700 \mathrm{~mA}$ ) with an excitation centered at $365 \mathrm{~nm}$ (UV-A). The averaged irradiance was $\sim 4 \mathrm{~mW} \cdot \mathrm{cm}^{-2}$.

The absorbance of the MB was monitored at intervals of 5 min using a spectrophotometer (ScanSpec UV-Vis, ScanSci) in the range of $300-900 \mathrm{~nm}$. The rate of photodegradation of $\mathrm{MB}$ was analyzed by monitoring the intensity variation of the main absorption peak at $665 \mathrm{~nm}$.

The kinetics of photocatalytic degradation of $\mathrm{MB}$ is a pseudo-first-order reaction and can be expressed according to the equation $[24,25]$ :

$$
\ln \left(\frac{C}{C_{0}}\right)=-k t
$$

where $C$ represents the dye's concentration at the time $t$, which is proportional to its optical absorbance, and $k$ is the first-order rate constant of the reaction.

2.4. Detection of Hydroxyl Radicals. Photoluminescence technique (PL) was used for the detection of hydroxyl radicals $\left({ }^{\circ} \mathrm{OH}\right)$ produced during the photocatalysis reaction. Coumarin was chosen as molecular probe, which readily reacted with ${ }^{\circ} \mathrm{OH}$ radicals to produce a highly fluorescent subproduct, 7-hydroxycoumarin (7HC), which shows a strong PL signal at $456 \mathrm{~nm}$ [26]. At room temperature, $5 \mathrm{mg}$ of photocatalyst powder was dispersed in $4 \mathrm{~mL}$ of $10^{-3} \mathrm{M}$ coumarin aqueous solution in a quartz cell $(40 \mathrm{~mm} \times$ $10 \mathrm{~mm} \times 10 \mathrm{~mm}$ ). The $\mathrm{pH}$ was adjusted to 3.3 with a $\mathrm{HCl}$ $0.1 \mathrm{M}$ solution. Initially, the coumarin solution with the modified $\mathrm{N}-\mathrm{TiO}_{2}$ and reference $\mathrm{P} 25$ particles was kept in dark for $30 \mathrm{~min}$ to establish adsorption-desorption equilibrium. After this stabilization period, and at given intervals of UV irradiation, the suspension was centrifuged and then analyzed on a FluoroLog-3 fluorescence spectrophotometer with an excitation wavelength of $332 \mathrm{~nm}$. The measurements were performed at room temperature and the emission and excitation slits were set to $2.0 \mathrm{~nm}$.

2.5. Polymeric Microcapsules. The microcapsules were prepared by using an adapted method based on interfacial polycondensation in an ultrasonic bath at a frequency of $30 \mathrm{kHz}[13,27,28]$. The encapsulation of dodecane into the microcapsules was achieved by the reaction between sebacoyl chloride and ethylenediamine, in presence of poly(vinyl) alcohol (PVA) as a surfactant. $415 \mu \mathrm{L}\left(6.2 \times 10^{-3} \mathrm{~mol}\right)$ of 
<smiles>CC(C)(C)NCCNC(=O)CCC(C)(C)C(=O)NCCC(C)(C)C(=O)Cl</smiles>

FIGURE 1: Scheme of the polymerization reaction.

ethylenediamine was added to the $25 \mathrm{~mL}$ of the $2 \%$ PVA solution. In the organic phase, $1.5 \mathrm{~mL}$ of dodecane and $265 \mu \mathrm{L}\left(1.2 \times 10^{-3} \mathrm{~mol}\right)$ of sebacoyl chloride were added drop by drop to the previous solution. The water/oil emulsion was emulsified for $5 \mathrm{~min}$ under the same ultrasonic conditions followed by 5 minutes under magnetic stirring at $300 \mathrm{rpm}$. The resulting microcapsules were rinsed several times with deionized water to remove the unreacted amine.

2.5.1. Characterization Methods. The gas chromatography coupled with mass spectrometry (GC-MS) analysis of dodecane output release from within the microcapsules was performed using a Varian 4000 Performance apparatus, equipped with a CP8944 VF-5 column and an ion trap mass spectrometer as detector. The carrier gas was helium, at a flow rate of $1 \mathrm{~mL} \cdot \mathrm{min}^{-1}$. Column temperature was initially $40^{\circ} \mathrm{C}$, and then gradually increased to $270^{\circ} \mathrm{C}$ at $8^{\circ} \mathrm{C} \cdot \mathrm{min}^{-1}$. For GCMS detection an electron impact ionization system was used with ionization energy of $70 \mathrm{eV}$.

The crystalline structure of the photocatalysts was characterized by X-ray diffraction analysis (XRD, Bruker D8 Discover diffractometer) using $\mathrm{Cu} \mathrm{K}_{\alpha}$ radiation. The morphological properties of microcapsules were studied using a scanning electron microscope (SEM, NanoSEM-FEI Nova 200) at SEMAT/UM. Fourier-transform infrared spectroscopy (FTIR) of vacuum-dried microcapsules loaded with optimized $\mathrm{N}$-doped $\mathrm{TiO}_{2}$ nanoparticles (at $30^{\circ} \mathrm{C}$ for 5 days) was performed at 132 scans and with a $4 \mathrm{~cm}^{-1}$ resolution between 500 and $4000 \mathrm{~cm}^{-1}$, using a JASCO 4200 FTIR spectrophotometer, operating in the ATR mode (MKII Golden Gate Single Reflection ATR System).

\section{Results and Discussion}

3.1. XRD Analysis. Figure 2 shows the XRD patterns of the prepared $\mathrm{N}$-doped $\mathrm{TiO}_{2}$ photocatalyst powders annealed at $300,500,700$, and $800^{\circ} \mathrm{C}$. The powders without calcination (curve a) exhibit an amorphous structure, with only minor traces of the most prominent anatase diffraction peaks. Therefore, the thermal treatment process is necessary to convert the amorphous $\mathrm{TiO}_{2}$ into a crystallized structure. For samples annealed at $300^{\circ} \mathrm{C}$ (curve b), clear diffraction peaks appear at $25.2^{\circ}$ and $37.8^{\circ}$, which are attributed to (101) and (004) lattice planes of the anatase structure, revealing the formation of crystalline anatase phase at an early stage of the heat treatment; the peak observed at $35^{\circ}$ is ascribed to $\mathrm{Ti}$ (100) planes. At this temperature no evidence of rutile

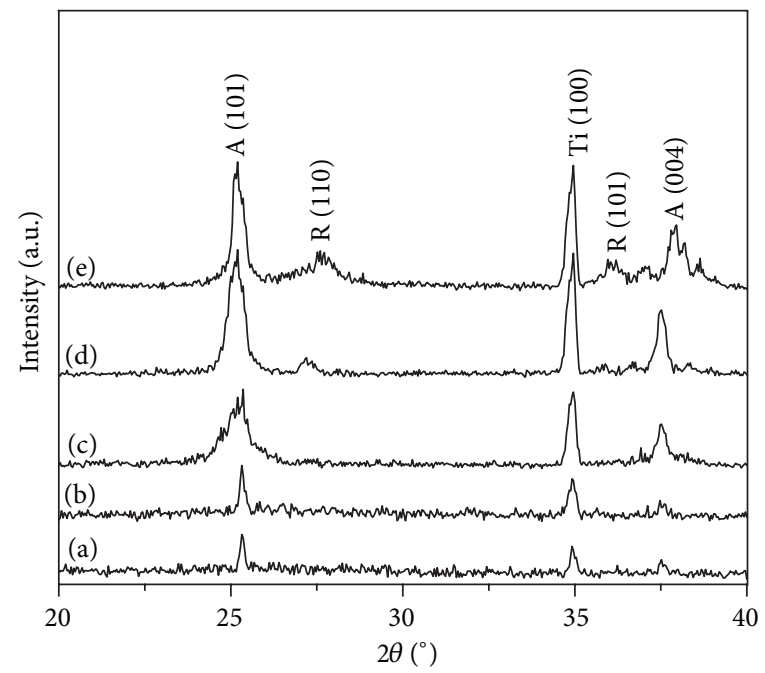

FIgURE 2: XRD patterns of the $\mathrm{N}$-doped $\mathrm{TiO}_{2}$ powders calcined at (a) room temperature (b) $300^{\circ} \mathrm{C} \mathrm{(c)} 500^{\circ} \mathrm{C}$, (d) $700^{\circ} \mathrm{C}$, and (e) $800^{\circ} \mathrm{C}$. A: anatase; R: rutile.

phase is discerned. Moreover, upon increasing the calcination temperature, the intensity of these anatase diffraction peaks also increases. However, for the highest temperature of $800^{\circ} \mathrm{C}$ (NP800-curve e) the diffraction peak associated with the rutile phase (110) at $27.5^{\circ}$ is more prominent, albeit lower than anatase preferential growth, indicating the starting transition of anatase phase to a more stable rutile phase. The diffraction pattern obtained for sample NP700 (curve d) is similar to the reference P25 material (not shown). The anatase average crystallite domain size varies very little with calcination temperature, increasing from $30 \mathrm{~nm}$ in its as-synthesized state to $50 \mathrm{~nm}$ for the highest temperature thermal treatment. At $800^{\circ} \mathrm{C}$ the rutile domain size is smaller than that corresponding to anatase, having a value of $\sim 37 \mathrm{~nm}$.

\subsection{Evaluation of the Photocatalytic Activity of the $\mathrm{TiO}_{2}$ Powders}

3.2.1. Adsorption of Methylene Blue on $\mathrm{TiO}_{2}$ Nanopowders. Comparative studies of the adsorption of methylene blue on the synthetized nanocatalyst powders were performed. A solution of methylene blue $\left(10^{-5} \mathrm{M}\right)$ was stirred with the different $\mathrm{TiO}_{2}$ nanoparticles $\left(0.15 \mathrm{~g} \cdot \mathrm{L}^{-1}\right)$ in the dark to ensure complete surface adsorption of dye. The change in methylene blue concentration was investigated by monitoring the 


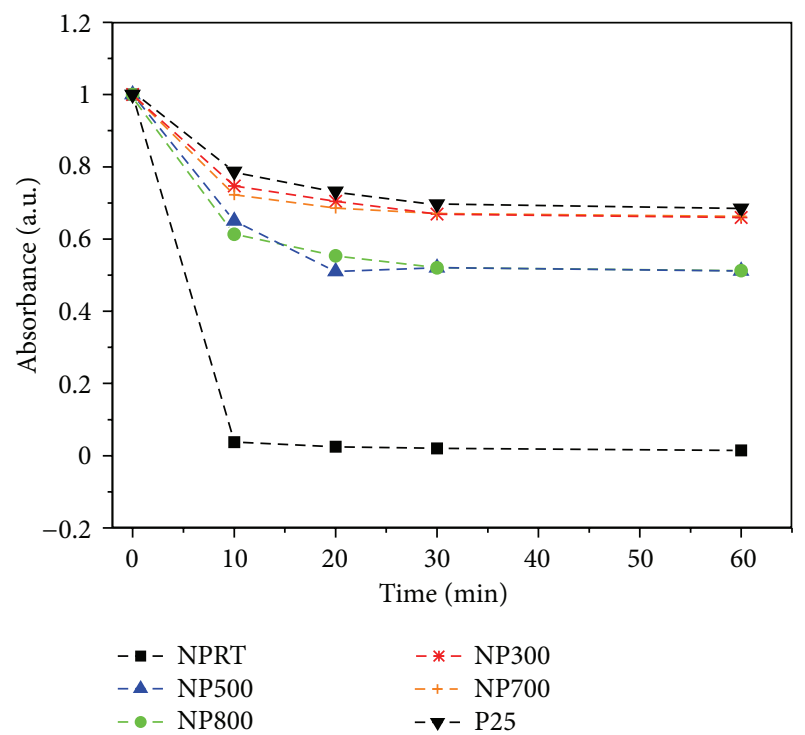

FIGURE 3: UV-vis absorption variation at $665 \mathrm{~nm}$ measured in the dark of $\mathrm{MB}\left(10^{-5} \mathrm{M}, \mathrm{pH}\right.$ 7.2) solution as a function of time for nano$\mathrm{TiO}_{2}$ powders annealed at different temperatures. This experiment has also been performed for the P25 reference powder.

maximum of absorbance of this dye at $665 \mathrm{~nm}$, as plotted in Figure 3. An important change can be observed after 10 minutes, where the absorbance of methylene blue drops from 2.33 to values lower than 1.85 , approximately $20 \%$ of the initial concentration value.

These results indicate that the $\mathrm{TiO}_{2}$ nanoparticles strongly adsorb the methylene blue molecules at the surface. This can be explained by the $\mathrm{pH}$ effect on methylene blue/ $/ \mathrm{TiO}_{2}$ nanoparticle suspensions. The $\mathrm{pH}$ of the solution influences significantly the characteristics of the $\mathrm{TiO}_{2}$ surface charge. Point of zero charge (PZC) is the value of $\mathrm{pH}$ at which the surface charge is zero. The knowledge of PZC of titania $(\mathrm{PZC}=$ 6.8) helps to predict the type and nature of the charge transfer that occurs preferentially. Since the photocatalytic assays were performed at $\mathrm{pH}$ higher than the reference $\mathrm{PZC}$ of titania, the surface of $\mathrm{TiO}_{2}$ nanoparticles has a negative charge and there is an electrostatic adsorption between negative-charged surfaces of $\mathrm{TiO}_{2}$ and methylene blue cations that carry a positive charge (2) [29-31]:

$$
\mathrm{TiOH}+\mathrm{OH}^{-} \longleftrightarrow \mathrm{TiO}^{-}+\mathrm{H}_{2} \mathrm{O} .
$$

Thus, Figure 3 further indicates that 30 minutes was sufficient to reach the adsorption equilibrium between methylene blue and $\mathrm{TiO}_{2}$ nanoparticles. Therefore, for all photocatalytic experiments, the dye solutions with $\mathrm{TiO}_{2}$ nanoparticles were first stirred in the dark for $30 \mathrm{~min}$ before UV-A irradiation assays.

3.2.2. Photocatalysis Assays. The photocatalytic reaction is very sensitive to the catalyst surface. The MB reacts with electrons and superoxide anions generated on the modified $\mathrm{TiO}_{2}$ particles under UV irradiation. The photocatalytic degradation reactions of $\mathrm{MB}$ on $\mathrm{UV}$ were investigated using

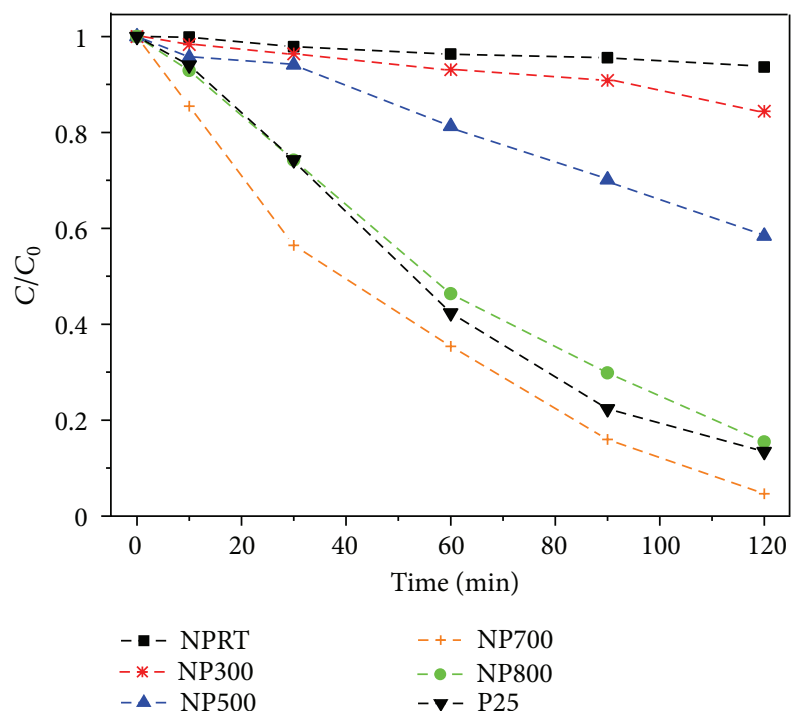

Figure 4: Photodegradation of $\mathrm{MB}\left(10^{-5} \mathrm{M}, \mathrm{pH}\right.$ 7.2) solution as a function of UV-A irradiation time for $\mathrm{TiO}_{2}$ powders annealed at different temperatures and reference P25.

TABLE 1: Rate constant $(k)$ and degradation (\%) of the MB $\left(10^{-5} \mathrm{M}\right.$, $\mathrm{pH}$ 7.2) solution for $\mathrm{TiO}_{2}$ powders annealed at different temperatures.

\begin{tabular}{lcc}
\hline Samples & $k$ values $\left(\mathrm{min}^{-1}\right)$ & $\begin{array}{c}\text { Degradation (\%) of MB solution } \\
\text { after } 120 \text { min. }\end{array}$ \\
\hline NPRT & - & 2 \\
NP300 & $1.6 \times 10^{-3}$ & 16 \\
NP500 & $6.0 \times 10^{-3}$ & 40 \\
NP700 & $2.4 \times 10^{-2}$ & 95 \\
NP800 & $1.5 \times 10^{-2}$ & 85 \\
TiO $_{2}$ P25 & $1.7 \times 10^{-2}$ & 88 \\
\hline
\end{tabular}

the prepared $\mathrm{N}$-doped $\mathrm{TiO}_{2}$ powders at different calcination temperature. In order to compare their UV light activities, the experiments were also carried out using the $\mathrm{TiO}_{2}$ powders without thermal treatment and the reference $\mathrm{TiO}_{2}$ P25 in the same way as using the $\mathrm{N}$-doped $\mathrm{TiO}_{2}$. The evolution of $\mathrm{MB}$ concentration with time for each sample at $665 \mathrm{~nm}$ is presented in Figure 4.

The photocatalytic degradation is a pseudo-first-order reaction and its kinetics, $k$ values (1), and the degradation (\%) of $\mathrm{MB}$ showing the catalytic activity of each sample are given in Table 1. Although $\mathrm{MB}$ was quickly degraded during UV-A irradiation for all the nanoparticles with thermal treatment, it is evident that NP700 showed the highest photocatalytic activity. The increased photocatalytic efficiency of the powders annealed at higher temperatures can be related to the surface morphology and crystal structure. This effect is attributed to the higher content of the crystalline anatase phase for the samples calcined at $700^{\circ} \mathrm{C}$ compared to those at 300 and $500^{\circ} \mathrm{C}$. According to the XRD results, the phase transformation from amorphous $\mathrm{TiO}_{2}$ to anatase was not complete at $300^{\circ} \mathrm{C}$. At $800^{\circ} \mathrm{C}$, some of 


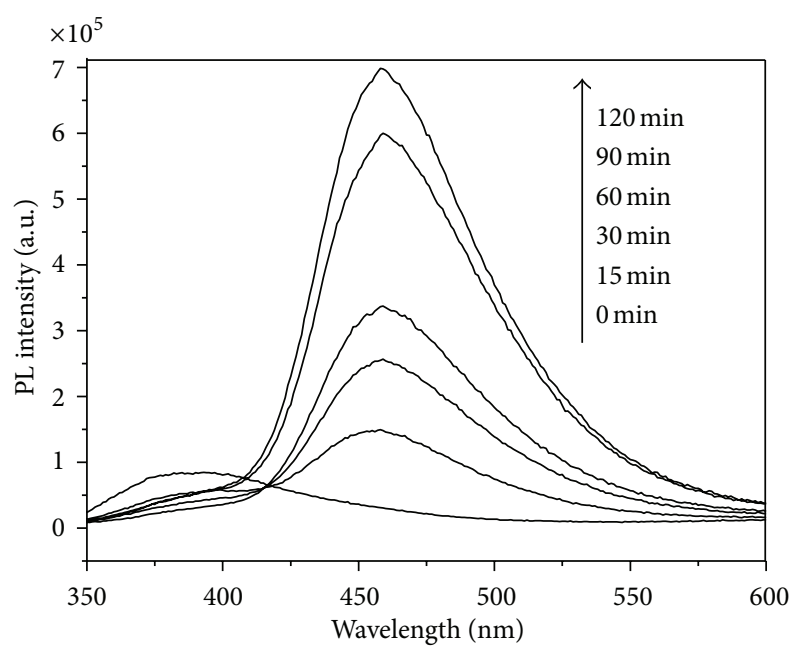

(a)

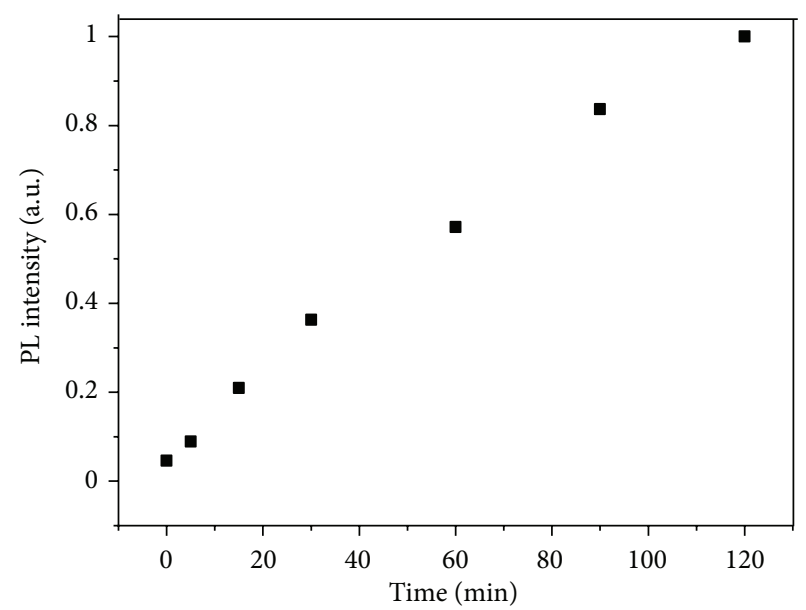

(b)

FIGURE 5: (a) Photoluminescence spectra of coumarin solution $\left(10^{-3} \mathrm{~mol} \mathrm{~L}^{-1}, \mathrm{pH} 3.3\right)$ after UV-A irradiation and (b) the time dependence of the photoluminescence intensity of 7-hydroxycoumarin at $456 \mathrm{~nm}$, in the presence of the NP700 powder.

anatase phase starts to transform to the more stable but photocatalytically less active rutile phase. The photolysis experiments (not shown), in the absence of $\mathrm{TiO}_{2}$ catalyst or samples without pre-treatment, revealed that the selfdegradation of $\mathrm{MB}$ was almost insignificant under UV-A illumination.

3.3. Photoluminescence of Coumarin. Under ultraviolet irradiation the valence-band electrons of $\mathrm{TiO}_{2}$ are excited to conduction band, leading to the formation of photogenerated electrons $\left(\mathrm{e}^{-}\right)$and holes $\left(\mathrm{h}^{+}\right)$pairs. In aqueous medium ${ }^{\circ} \mathrm{OH}$ radicals are generated by the reaction between photogenerated holes and $\mathrm{H}_{2} \mathrm{O}$. Related reactions may be summarized as follows:

$$
\begin{gathered}
\mathrm{TiO}_{2}+\mathrm{h} v \longrightarrow \mathrm{h}^{+}+\mathrm{e}^{-}, \\
\mathrm{O}_{2}+\mathrm{e}^{-} \longrightarrow \mathrm{O}_{2}^{-}, \\
\mathrm{H}_{2} \mathrm{O}+\mathrm{h}^{+} \longrightarrow \cdot \mathrm{OH}+\mathrm{H}^{+} .
\end{gathered}
$$

The detection by coumarin fluorescence is based on the fact that its hydroxylation generates various subproducts, in which only one is strongly fluorescent, 7-hydroxycoumarin, as follows:

$$
\text { Coumarin }+^{\bullet} \mathrm{OH} \longrightarrow 7 \text {-Hydroxycoumarin. }
$$

After the correction of the coumarin PL signal, which is almost negligible, the 7-hydroxycoumarin fluorescence signal can be used to determine the quantity of ${ }^{\circ} \mathrm{OH}$ generated in reaction. Figure 5 shows the changes of PL spectra from a coumarin solution with UV-A irradiation time in the presence of NP700. It is evident that a gradual increase in the fluorescence occurs over the time at $\sim 456 \mathrm{~nm}$. This signal can be related to 7-hydroxycoumarin and suggests that fluorescent product was formed during $\mathrm{TiO}_{2}$ photocatalysis due to

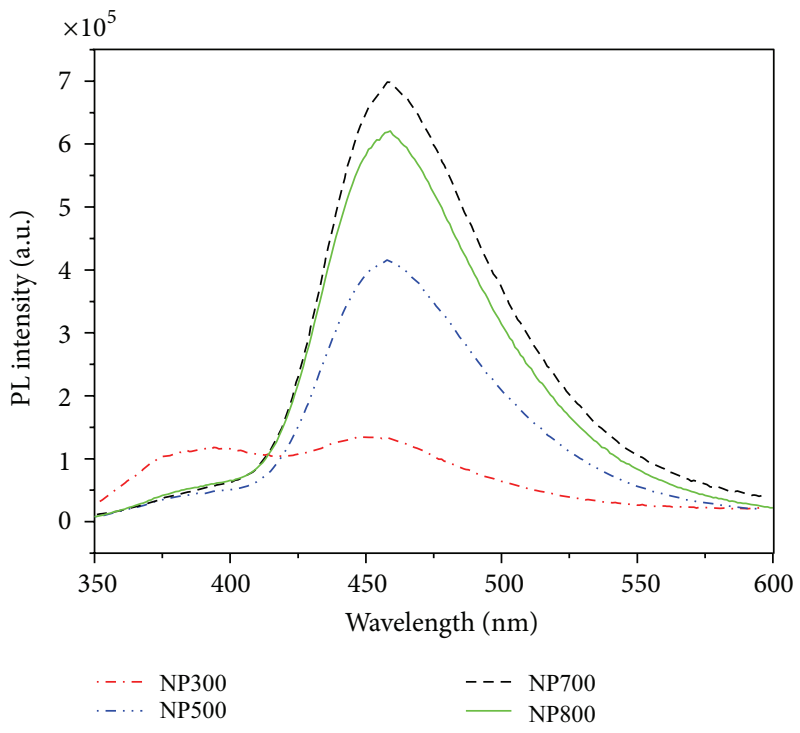

FIgURE 6: Photoluminescence spectra of coumarin solution $\left(10^{-3} \mathrm{~mol} \mathrm{~L}^{-1}, \mathrm{pH} 3.3\right)$ after $120 \mathrm{~min}$ of UV-A irradiation in the presence of $\mathrm{N}-\mathrm{TiO}_{2}$ powders annealed at different temperatures.

the specific reaction between hydroxyl radical and coumarin. It is clearly seen in Figure 5(b) that the fluorescence intensity increases linearly with the irradiation time.

In order to investigate the effect of temperature annealing on the formation rate of radicals, PL experiments were performed in same conditions of NP700 for all N-doped $\mathrm{TiO}_{2}$ prepared by sol-gel method. After $2 \mathrm{~h}$ of irradiation PL spectra were recorded and compared (Figure 6).

It is clear that the NP700 sample yields a higher PL intensity, implying a high formation rate of $7 \mathrm{HC}$ and ${ }^{\circ} \mathrm{OH}$. It is interesting to note that the PL intensity decreased when 


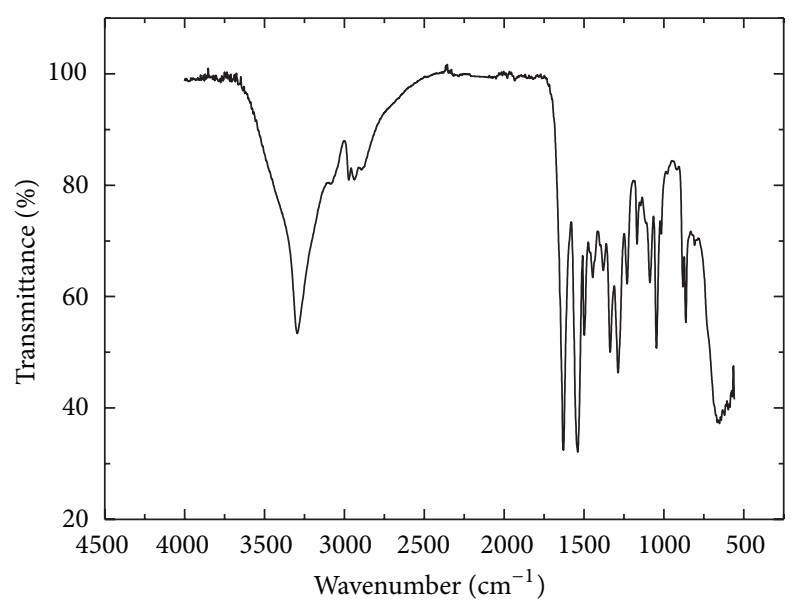

FIGURE 7: IR spectra of microcapsules with $\mathrm{TiO}_{2}$ prepared by interfacial polymerization.

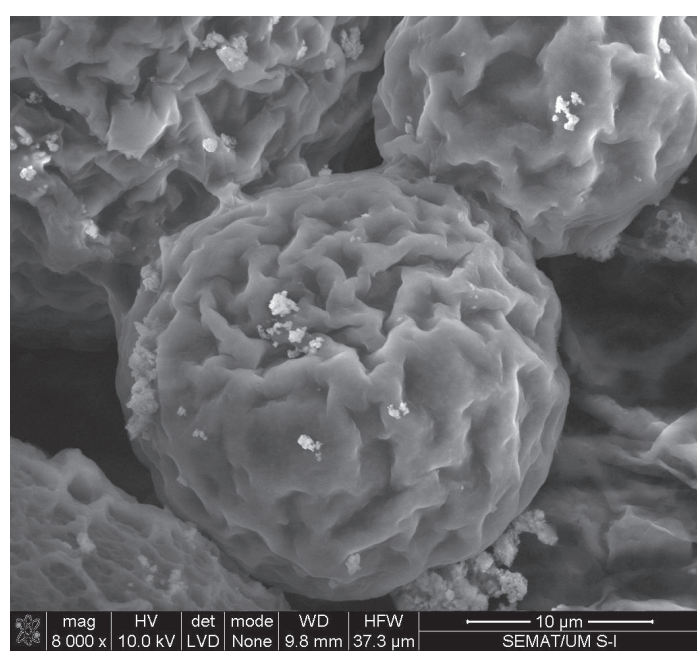

(a)

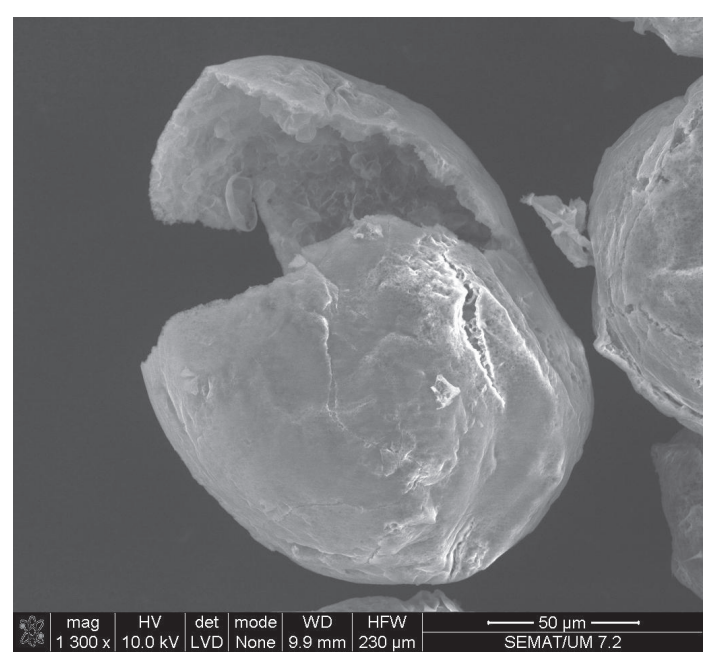

(b)

FIGURE 8: Scanning electron microscopy micrographs of dodecane-loaded polyamide microcapsules (a) with $\mathrm{N}_{\text {-doped }} \mathrm{TiO}_{2}$ nanoparticles adsorbed onto its surface and (b) microcapsule degradation upon UV-A irradiation.

NP800 was used. This can be explained by the fact that NP800 contains a two-phase mixture of anatase and rutile, which can be related to the increase of the recombination in photogenerated electrons and holes and subsequently block of ${ }^{\circ} \mathrm{OH}$ production on the $\mathrm{TiO}_{2}$ surface. The ${ }^{\circ} \mathrm{OH}$ formation rate on rutile phase is much lower than that on anatase phase. The observed PL signal was lower for calcined powders at temperatures below $700^{\circ} \mathrm{C}$, meaning that a prominent anatase phase is directly correlated with enhanced ${ }^{\circ} \mathrm{OH}$ production.

3.4. FTIR-ATR Analysis of Polyamide Microcapsules. The FTIR spectrum of the synthesized polyamide microcapsules functionalized with $\mathrm{TiO}_{2}$ is presented in Figure 7.

Figure 7 presents the absorption band related with $-\mathrm{C}=\mathrm{O}$ stretching vibration of the secondary amide group at
$1630 \mathrm{~cm}^{-1}$ and the corresponding $\mathrm{N}-\mathrm{H}$ stretching vibration at $1544 \mathrm{~cm}^{-1}$, which shows the success of the interfacial polymerization, with formation of polyamide.

The spectral region between 3500 and $3060 \mathrm{~cm}^{-1}$ corresponds to the $-\mathrm{NH}$ stretching vibration of the primary and secondary amines, which could be related to the excess of amine used. The large band at $3310 \mathrm{~cm}^{-1}$ is ascribed to the $-\mathrm{C}=\mathrm{O}$ characteristic band. The peaks from $2970 \mathrm{~cm}^{-1}$ to $2830 \mathrm{~cm}^{-1}$ are attributed to the $\mathrm{TiO}_{2}$ showing that the nanoparticles were successfully adsorbed on the surface.

3.5. SEM Analysis of Polymeric Microcapsules. Figure 8 shows a SEM micrograph of the microcapsules (a) with $\mathrm{N}$-doped $\mathrm{TiO}_{2}$ powders adsorbed onto polymeric wall and (b) microcapsule degradation upon UV-A irradiation. The resulting microcapsules have sizes ranging from $20-100 \mu \mathrm{m}$ 


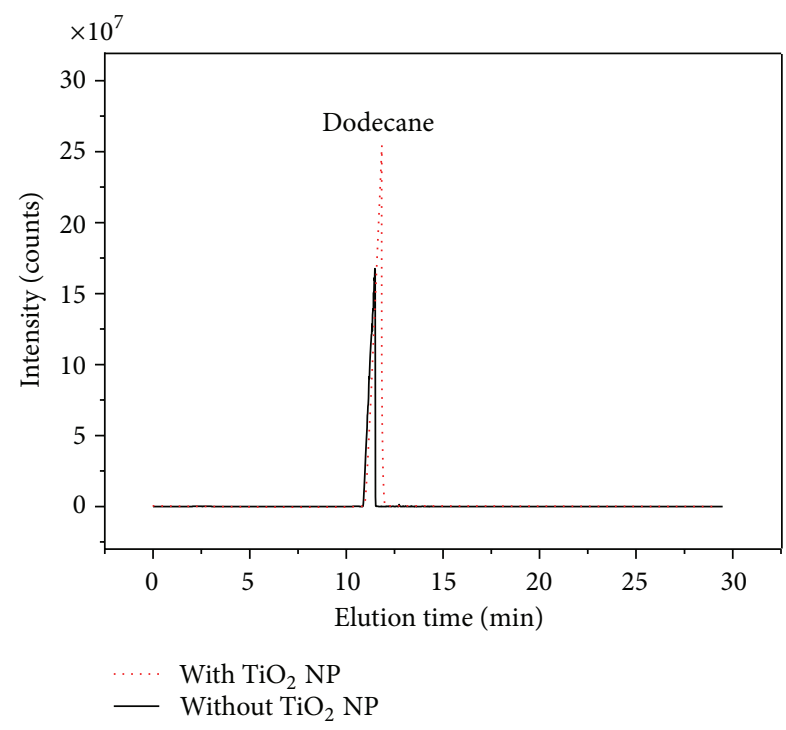

FIGURE 9: Chromatograms obtained by GC-MS for UV-A-irradiated dodecane-loaded polyamide microcapsules in the presence and absence of $\mathrm{N}$-doped $\mathrm{TiO}_{2}$ nanoparticles (NP700).

and spherical shape with a porous surface. The results presented in Figure 8(b) suggest that the microcapsule wall collapses after $2 \mathrm{~h}$ under UV-A irradiation. This can be related to the photocatalyst-driven oxidation-redution mechanisms that are developed on the catalyst surface and subsequent - $\mathrm{OH}$ radicals production that initiate the dissociation and subsequent breach of the polymeric wall.

3.6. Evaluation of Dodecane Release by GC-MS. The GCMS analysis of the UV-A-irradiated samples containing dodecane-loaded microcapsules adsorbed with $\mathrm{TiO}_{2}$ nanoparticles on the surface revealed the presence of dodecane as a principal compound from the output yield. In order to compare the results with a commercial sample of $\mathrm{TiO}_{2} \mathrm{P} 25$, GC-MS experiments were performed only for the sample NP700, since it showed the best results in the photocatalysis and photoluminescence assays discussed before (Figures 4 and 6). Figure 9 shows the chromatograms obtained by GCMS for irradiated microcapsules in the presence and absence of photocatalyst nanoparticles, while Figure 10 demonstrates the UV-A illumination effect on the output release of dodecane from within the aforementioned microcapsules adsorbed with the photocatalyst nanoparticles.

From the analysis of Figures 9 and 10 it is demonstrated that the integrated area of dodecane peak is much higher when the microcapsules are adsorbed with the photocatalyst nanoparticles and under UV-A irradiation. These results strengthen the fact that under UV-A irradiation the surface of photocatalyst develops oxidation-reduction processes that originate the cleave of chemical bonds and thus the collapse of the polymeric capsule, yielding the release of the volatile compound (dodecane).

Figure 11 shows the output release concentrations in $\mathrm{ppm}$ of dodecane from the polyamide microcapsules, for different

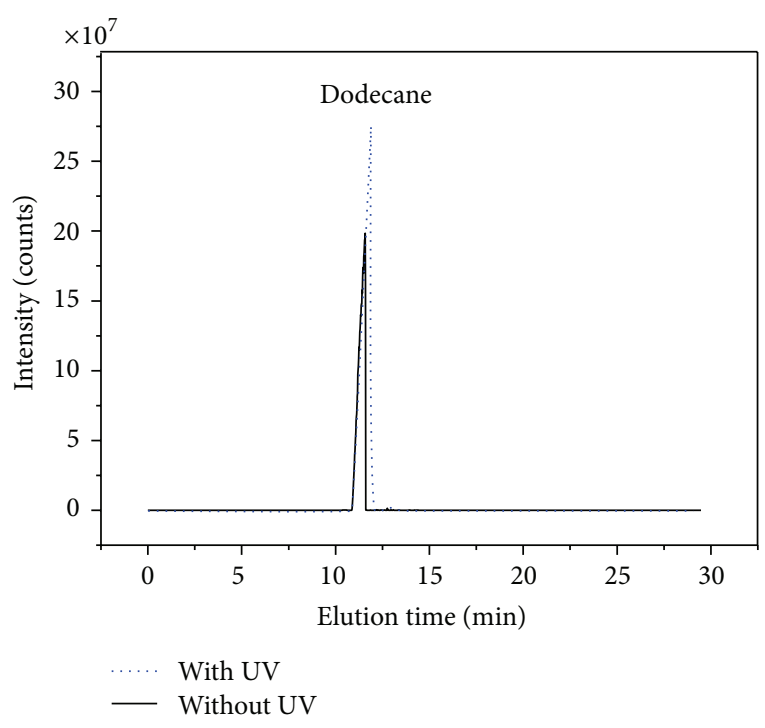

FIGURE 10: GC-MS chromatograms obtained for dodecane-loaded polyamide microcapsules adsorbed with $\mathrm{N}$-doped $\mathrm{TiO}_{2}$ nanoparticles (NP700), with and without UV-A irradiation.

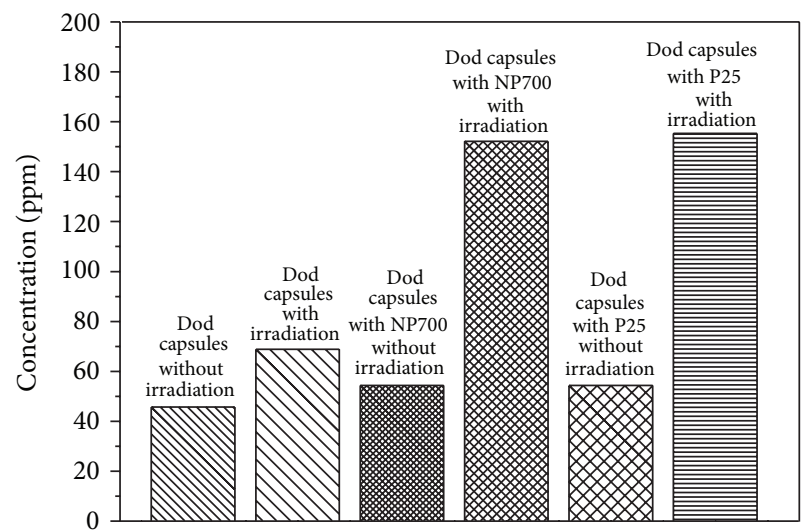

FIGURE 11: Concentration (ppm) of the output release of dodecane (Dod) from the polyamide microcapsules, for different samples and experimental conditions.

samples and experimental conditions. Due to the fact that these polymeric capsules may have some porosity, since the synthesis process is not fully optimized, it was found that dodecane can be released slowly either without the presence of the $\mathrm{TiO}_{2}$ nanoparticles or in its presence but without UV-A irradiation. The irradiation of the microcapsules with UV-A alone, in absence of titanium dioxide, is expected to degrade the polymeric wall, releasing the dodecane. However, upon the UV-A irradiation, the release rate of the volatile agent is much higher. The results obtained for the NP700 and $\mathrm{TiO}_{2} \mathrm{P} 25$ confirm that nanoparticles prepared in this work present similar efficiency when compared with the commercial sample.

\section{Conclusions}

A simple method was developed for the synthesis of a stable nanocrystalline $\mathrm{N}$-doped $\mathrm{TiO}_{2}$ photocatalysts by a modified 
sol-gel method, which were adsorbed on dodecane-loaded polyamide-based microcapsules. The effect of annealing temperature on the photocatalytic activity of the nanoparticles under ultraviolet irradiation was investigated. It was found that photocatalytic activity of these nanoparticles is strongly dependent on the calcination temperature. The nanoparticles calcined at $700^{\circ} \mathrm{C}$ revealed the highest photocatalytic activity upon degrading methylene blue under UV-A irradiation. Furthermore, the formation of ${ }^{\circ} \mathrm{OH}$ radicals on the photocatalyst surface under UV-A irradiation was also monitored by fluorescence experiments. In the same way of $\mathrm{MB}$ degradation, the $\mathrm{N}$-doped $\mathrm{TiO}_{2}$ powders calcined at $700^{\circ} \mathrm{C}$ form a higher number of hydroxyl radicals on its surface than powders annealed at lower and higher temperatures $\left(800^{\circ} \mathrm{C}\right)$. This result can be related to the more stable and prominent anatase phase in this sample, in detriment to rutile formation at a higher temperature.

This work has shown that polyamide based microcapsules with $\mathrm{TiO}_{2}$ adsorbed on the surface can be successfully used to trigger the release of a model organic volatile compounds by UV-A irradiation. By means of GC-MS experiments it was possible to identify and quantify the amount of volatile compound released.

The proof of concept presented in this work can be extended to afford the preparation of microcapsules loaded with organic compounds that can be released in a controlled manner through UV-A irradiation.

\section{Acknowledgments}

This work was supported by FEDER through the COMPETE Program and by the Portuguese Foundation for Science and Technology (FCT) in the framework of the Strategic Project PEST-C/FIS/UI607/2011 and PTDC/CTMNAN/119979/2010 Project.

\section{References}

[1] T. Brandau, "Preparation of monodisperse controlled release microcapsules," International Journal of Pharmaceutics, vol. 242, no. 1-2, pp. 179-184, 2002.

[2] K. Aiedeh, E. Gianasi, I. Orienti, and V. Zecchi, "Chitosan microcapsules as controlled release systems for insulin," Journal of Microencapsulation, vol. 14, no. 5, pp. 567-576, 1997.

[3] U. Jeong, S. H. Im, P. H. C. Camargo, J. H. Kim, and Y. Xia, "Microscale fish bowls: a new class of latex particles with hollow interiors and engineered porous structures in their surfaces," Langmuir, vol. 23, no. 22, pp. 10968-10975, 2007.

[4] R. Dubey, T. C. Shami, and K. U. Bhasker Rao, "Microencapsulation technology and applications," Defence Science Journal, vol. 59, no. 1, pp. 82-95, 2009.

[5] D. G. Yu, S. H. Kim, and J. H. An, "Preparation and characterization of electronic inks encapsulation for microcapsuletype electrophoretic displays (EPDs)," Journal of Industrial and Engineering Chemistry, vol. 13, no. 3, pp. 438-443, 2007.

[6] H. Bungerberg de Jong, "Crystallization-coacervation-flocculation," Colloid Science, vol. 2, pp. 280-283, 1949.

[7] S. Leclercq, K. R. Harlander, and G. A. Reineccius, "Formation and characterization of microcapsules by complex coacervation with liquid or solid aroma cores," Flavour and Fragrance Journal, vol. 24, no. 1, pp. 17-24, 2009.

[8] F. Tiarks, K. Landfester, and M. Antonietti, "Preparation of polymeric nanocapsules by miniemulsion polymerization," Langmuir, vol. 17, no. 3, pp. 908-918, 2001.

[9] R. Arshady, "Microspheres and microcapsules, a survey of manufacturing techniques. Part III. Solvent evaporation," Polymer Engineering and Science, vol. 30, no. 15, pp. 915-924, 1990.

[10] H. Strohm, M. Sgraja, J. Bertling, and P. Löbmann, "Preparation of $\mathrm{TiO}_{2}$-polymer hybrid microcapsules," Journal of Materials Science, vol. 38, no. 8, pp. 1605-1609, 2003.

[11] A. Toubeli and C. Kiparissides, "Synthesis and characterization of polyterephthalamide membranes for encapsulation use: effect of the amine type and composition on the membrane permeability," Journal of Membrane Science, vol. 146, no. 1, pp. 15-29, 1998.

[12] P. Persico, C. Carfagna, L. Danicher, and Y. Frere, "Polyamide microcapsules containing jojoba oil prepared by inter-facial polymerization," Journal of Microencapsulation, vol. 22, no. 5, pp. 471-486, 2005.

[13] M. L. Soto-Portas, J. F. Argillier, F. Méchin, and N. Zydowicz, "Preparation of oily core polyamide microcapsules via interfacial polycondensation," Polymer International, vol. 52, no. 4, pp. 522-527, 2003.

[14] C. J. Tavares and F. J. S. Pina, "Photocatalytic coating for the controlled release of volatile agents," International Patent WO 2011/012935 A2, PCT/IB2009/055716, World Intellectual Property Organization, 2011.

[15] M. A. Fox and M. T. Dulay, "Heterogeneous photocatalysis," Chemical Reviews, vol. 93, no. 1, pp. 341-357, 1993.

[16] A. L. Linsebigler, G. Lu, and J. T. Yates, "Photocatalysis on $\mathrm{TiO}_{2}$ surfaces: principles, mechanisms, and selected results," Chemical Reviews, vol. 95, no. 3, pp. 735-758, 1995.

[17] R. Asahi, T. Morikawa, T. Ohwaki, K. Aoki, and Y. Taga, "Visible-light photocatalysis in nitrogen-doped titaniu oxides," Science, vol. 293, no. 5528, pp. 269-271, 2001.

[18] C. Cantau, T. Pigot, J. C. Dupin, and S. Lacombe, "N-doped $\mathrm{TiO}_{2}$ by low temperature synthesis: stability, photo-reactivity and singlet oxygen formation in the visible range," Journal of Photochemistry and Photobiology A, vol. 216, no. 2-4, pp. 201208, 2010.

[19] X. Zhanga K, udagawab, Z. Liua et al., "Photocatalytic and photoelectrochemical studies on $\mathrm{N}$-doped $\mathrm{TiO}_{2}$ photocatalyst," Journal of Photochemistry and Photobiology A, vol. 202, no. 1, pp. $39-47,2009$.

[20] T. Ihara, M. Miyoshi, Y. Iriyama, O. Matsumoto, and S. Sugihara, "Visible-light-active titanium oxide photocatalyst realized by an oxygen-deficient structure and by nitrogen doping," Applied Catalysis B, vol. 42, no. 4, pp. 403-409, 2003.

[21] B. Fu, L. Gao, and S. Yang, "CNTs/Ta3N5 nanocomposite with enhanced photocatalytic activity under visible light irradiation," Journal of the American Ceramic Society, vol. 90, no. 4, pp. 13091311, 2007.

[22] Y. Cong, L. Xiao, J. Zhang, F. Chen, and M. Anpo, "Preparation and characterization of nitrogen-doped $\mathrm{TiO}_{2}$ photocatalyst in different acid environments," Research on Chemical Intermediates, vol. 32, no. 8, pp. 717-724, 2006.

[23] A. Mills and J. Wang, "Photobleaching of methylene blue sensitised by $\mathrm{TiO}_{2}$ : an ambiguous system?" Journal of Photochemistry and Photobiology A, vol. 127, no. 1-3, pp. 123-134, 1999. 
[24] H. Hashemipour and M. Mirzaee, "Experimental study of influencing factors and kinetics in catalytic removal of methylene blue with $\mathrm{TiO}_{2}$ nanopowder," American Journal of Environmental Engineering, vol. 2, no. 1, pp. 1-7, 2012.

[25] C. H. Wu and J. M. Chern, "Kinetics of photocatalytic decomposition of methylene blue," Industrial and Engineering Chemistry Research, vol. 45, no. 19, pp. 6450-6457, 2006.

[26] H. Czili and A. Horváth, "Applicability of coumarin for detecting and measuring hydroxyl radicals generated by photoexcitation of $\mathrm{TiO}_{2}$ nanoparticles," Applied Catalysis B, vol. 81, no. 3-4, pp. 295-302, 2008.

[27] H. Essawy and K. Tauer, "Polyamide capsules via soft templating with oil drops-1. Morphological studies of the capsule wall," Colloid and Polymer Science, vol. 288, no. 3, pp. 317-331, 2010.

[28] I. Hanno, C. Anselmi, and K. Bouchemal, "Polyamide nanocapsules and nano-emulsions containing Parsol MCX and Parsol 1789: in vitro release, ex vivo skin penetration and photostability studies," Pharmaceutical Research, vol. 29, pp. 559-573, 2012.

[29] A. H. Mahvi, M. Ghanbarian, S. Nasseri, and A. Khairi, "Mineralization and discoloration of textile wastewater by $\mathrm{TiO}_{2}$ nanoparticles," Desalination, vol. 238, no. 1-3, pp. 309-316, 2009.

[30] H. Kumazawa, H. Otsuki, and E. Sada, "Preparation of monosized spherical titania fine particles by controlled hydrolysis of titanium tetraethoxide in ethanol," Journal of Materials Science Letters, vol. 12, no. 11, pp. 839-840, 1993.

[31] A. Houas, H. Lachheb, M. Ksibi, E. Elaloui, C. Guillard, and J. M. Herrmann, "Photocatalytic degradation pathway of methylene blue in water," Applied Catalysis B, vol. 31, no. 2, pp. 145-157, 2001. 

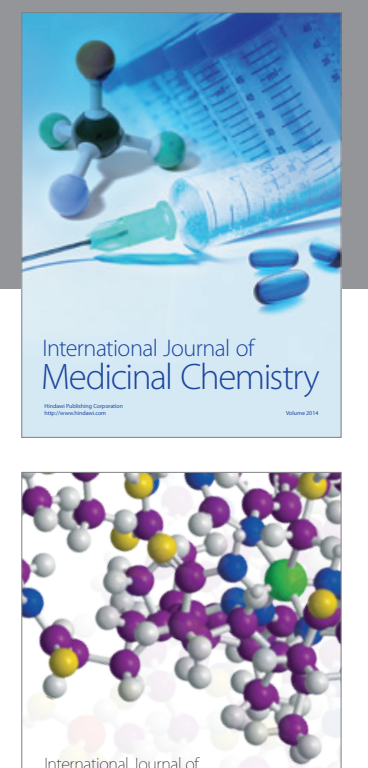

\section{Carbohydrate} Chemistry

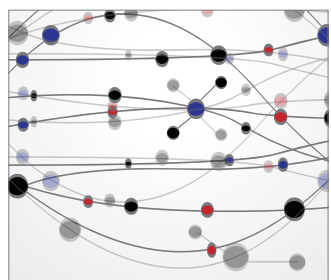

The Scientific World Journal
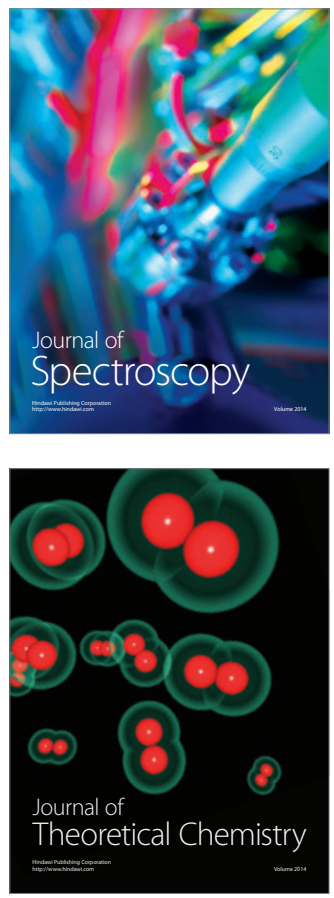
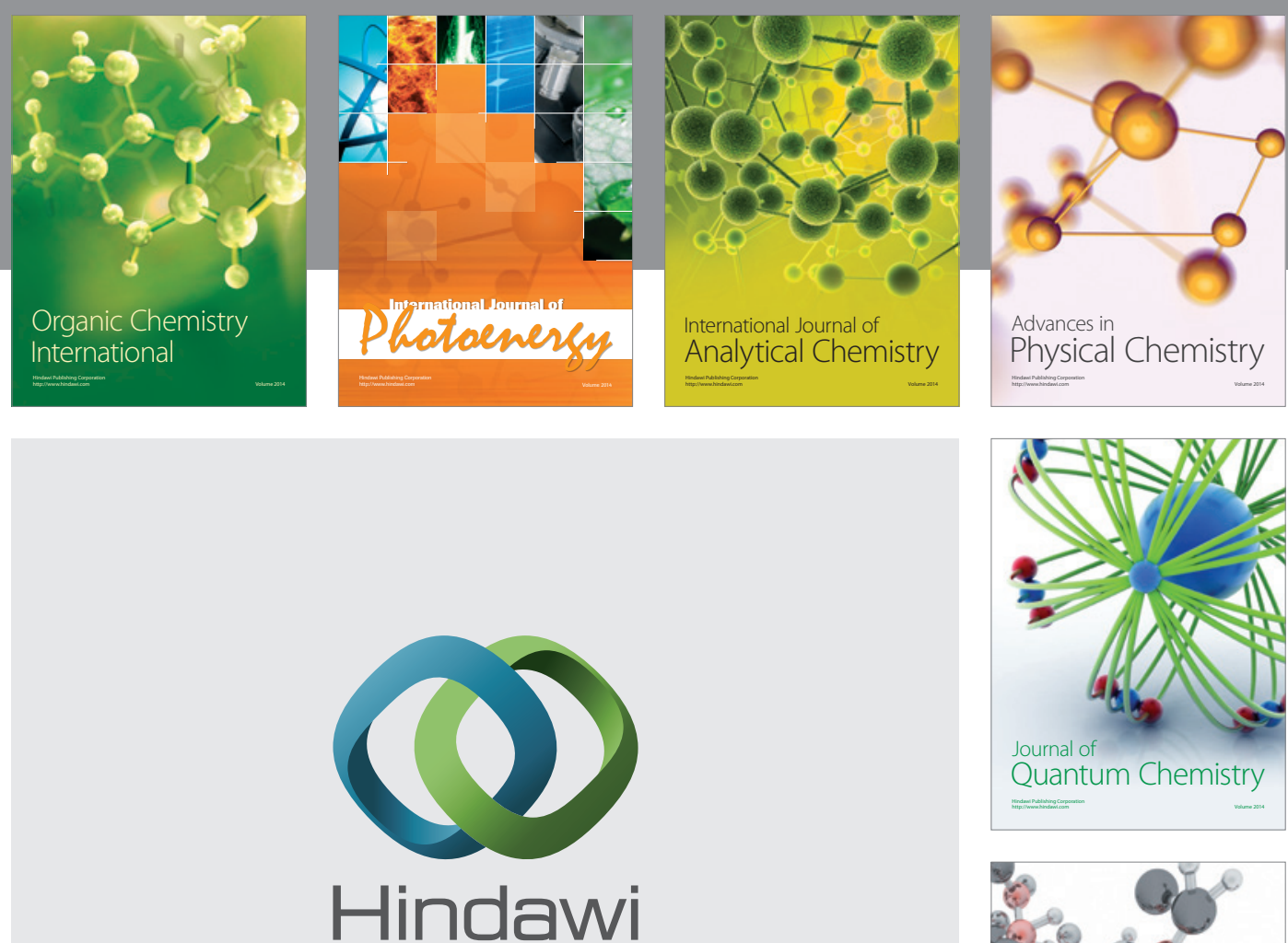

Submit your manuscripts at

http://www.hindawi.com

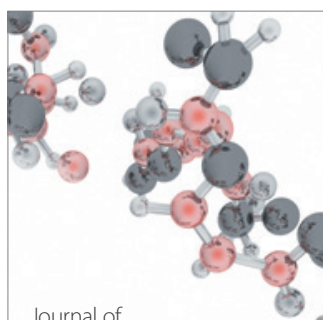

Analytical Methods

in Chemistry

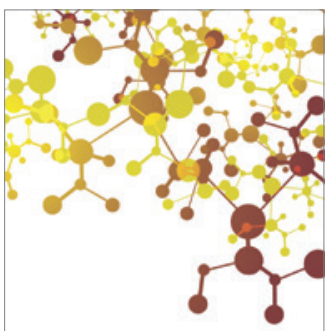

Journal of

Applied Chemistry

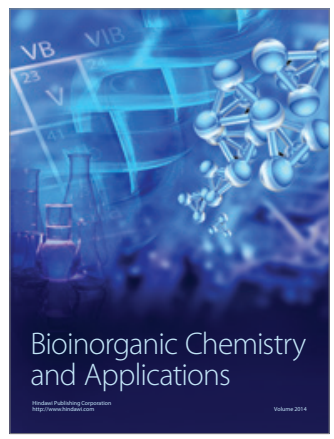

Inorganic Chemistry
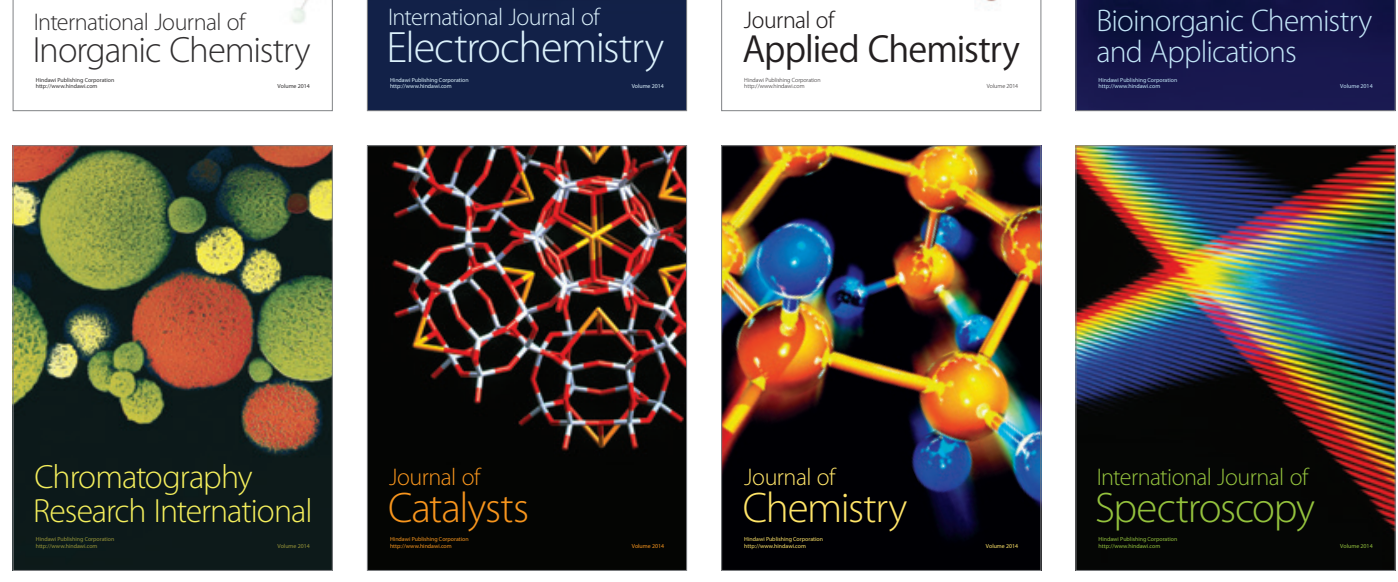